\title{
Attitude control of an inverted-pendulum-type robotic wheelchair to climb stairs considering dynamic equilibrium
}

\author{
Yuya Onozuka ${ }^{*^{*} \mathbb{D}}$, Nobuyasu Tomokuni ${ }^{2}$, Genki Murata ${ }^{3}$ and Motoki Shino ${ }^{1}$
}

\begin{abstract}
The wheelchair is the major means of transport for elderly and physically disabled people in their daily lives. However it cannot overcome architectural barriers such as curbs and stairs. In this study, we developed an inverted-pendulumtype robotic wheelchair for climbing stairs. This wheelchair has a seat slider and two rotary links between the front and rear wheels on each side. When climbing stairs, the wheelchair rotates the rotary links while maintaining an inverted state of a mobile body by controlling the position of the center of gravity using a seat slider. In previous research, we confirmed that the wheelchair can climb by applying the control method consisting of a center-of-gravity control phase and rotary link control phase. However, it took approximately $15 \mathrm{~s}$ to rotate the rotary links during climbing because faster climbing causes the movement of wheels and the wheelchair to fall. This paper focuses on a control method to restrain the movement of the wheels when the stair climbing speed is increased. We realized that the movement was caused by forces acting on the pitch angle, such as the inertial force and the reaction of the driving force. We proposed the method considering the dynamic equilibrium of the pitch angle and confirmed the effect of the restraining wheels' movement when the proposed method was applied.
\end{abstract}

Keywords: Wheeled Robot, Climbing stairs, Inverted pendulum, Attitude control, Dynamics

\section{Introduction}

In recent years, the number of elderly people and physically disabled people has increased, and the demand for Electric powered wheelchairs (EPWs) has also witnessed an increase. However, as it is difficult to access some areas that have curbs and stairs when using a standard EPW, the range of activities is limited compared to that of healthy people, leading to a decline in the quality of life. Therefore, several mechanisms have been developed that can access these areas without requiring assistance from a caregiver. The characteristics of these mechanisms

\footnotetext{
*Correspondence: onozuka.yuya@atl.k.u-tokyo.ac.jp

1 Department of Human and Engineered Environmental Studies, Graduate School of Frontier Sciences, The University of Tokyo, 5-1-5

Kashiwanoha, Kashiwa, Chiba, Japan

Full list of author information is available at the end of the article
}

differ depending on the grounding method and are classified into three categories: crawler-type mechanism, multipoint-grounding-type mechanism, and a two-pointgrounding-type mechanism.

SCEWO [1] employs a mechanism that combines a crawler and wheels; the crawler is used when climbing stairs and the wheels are used traveling on a flat ground. The ground contact surface at the time of climbing stairs on the crawler is only at the edge of the stairs. For this reason, it is considered desirable to use stairs with small gradients. The RT-Mover [2] and MEBot [3] are examples of multipoint-grounding-type mechanisms that maintain static stability by creating three or more ground contact points when climbing stairs. These mechanisms allow for safe climbing because static stability is maintained at all times. However, there are several actions that need to be
Springer Open

(c) The Author(s) 2020. This article is licensed under a Creative Commons Attribution 4.0 International License, which permits use, sharing adaptation, distribution and reproduction in any medium or format, as long as you give appropriate credit to the original author(s) and the source, provide a link to the Creative Commons licence, and indicate if changes were made. The images or other third party material in this article are included in the article's Creative Commons licence, unless indicated otherwise in a credit line to the material. If material is not included in the article's Creative Commons licence and your intended use is not permitted by statutory regulation or exceeds the permitted use, you will need to obtain permission directly from the copyright holder. To view a copy of this licence, visit http://creativeco mmons.org/licenses/by/4.0/. 
executed for climbing stairs, which renders stair climbing time-consuming. In addition, as the mechanism is complicated and the size of the undercarriage is large, some stairs are impossible to climb depending on the length of the tread. iBOT [4] utilizes a two-point-grounding-type mechanism composed of two right and left wheels and a rotary link that connects the front and rear wheels on each side. The iBOT climbs by repeating four- and twopoint grounding states. It is possible to climb in roughly 3 s per step regardless of the slope of the stairs and the length of the tread. However, as it is in a statically unstable state of two-point grounding on the stairs, it is necessary for a passenger to hold the handrail to maintain balance to climb stairs without the assistance of a caregiver [4]. Therefore, iBOT is unsuitable as a mobility support device for elderly people with limited lower- and upper-body function.

The wheelchair proposed by Shino et al. (Fig. 1) utilizes a two-point-grounding-type mechanism similar to the iBOT and climbs using the control theory of an inverted pendulum. As a feature, it has a slider mechanism to control the center-of-gravity position. It is different from the $\mathrm{iBOT}$ in that the adjustment of balance is autonomously accomplished, and therefore does not require assistance from caregivers or the training of passengers. In previous research using this mechanism, a controller was implemented to maintain the pitch angle at zero without falling over on the stairs [5-7]. Consequently, stability was ensured under the condition that it took approximately $15 \mathrm{~s}$ to ascend a single step. However, two-point-grounding-type mechanisms have fewer degrees of freedom and are simpler than multipoint-grounding-type mechanisms. Therefore, the former should be able to climb faster. In fact, although it is not a boarding-type robot,

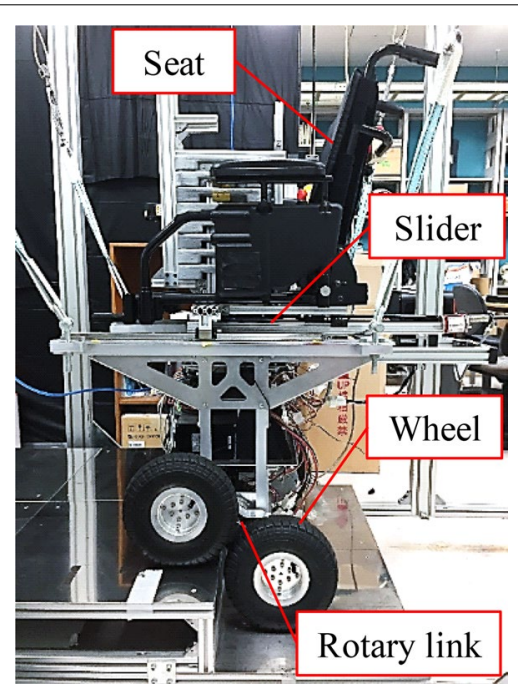

Fig. 1 Proposed inverted-pendulum-type robotic wheelchair [5] there have been studies aiming at stair ascending and descending such that the grounding wheels do not move more than the length of the stairs when using a twopoint-grounding-type mechanism [8-10]. In this paper, we clarify the characteristics of the behavior of the mechanism when increasing the stair climbing speed and propose an attitude (pitch angle) control strategy that takes this characteristic into account.

\section{Mechanism design}

Front and side views of the mechanism proposed by Shino et al. are depicted in Fig. 2, and its specification are listed in Table 1. As shown in Fig. 2, the proposed mechanism comprises two rotary links between the front and rear wheels on each side, and a slider that moves the seat back and forth. As a result of previous experiments to examine the response of the occupant when the seat is vibrated up and down and back and forth by using a 6-DoF motion platform as shown in Fig. 3, it has been confirmed that the response of the occupant is small in the frequency band when climbing stairs [11]. In addition, the user is assumed to be fixed to the seat with a seat belt. Therefore, a payload can substitute the real user. The device has a slider actuator under the seat and rotary links and wheel-drive motors. Shino et al. [5] evaluated stair climbing with these actuators, confirming that each

Table 1 Specifications of developed EPW

\begin{tabular}{ll}
\hline Parameter & Value \\
\hline Height & $1245-1375 \mathrm{~mm}$ \\
Length & $1055-1175 \mathrm{~mm}$ \\
Width & $732 \mathrm{~mm}$ \\
Weight (without payload) & $90 \mathrm{~kg}$ \\
Maximum thrust of slider actuator & $895 \mathrm{~N}$ \\
Maximum motor torque of rotary link & $150 \mathrm{Nm}$ \\
Maximum motor torque of wheel drive & $10 \mathrm{Nm}$
\end{tabular}

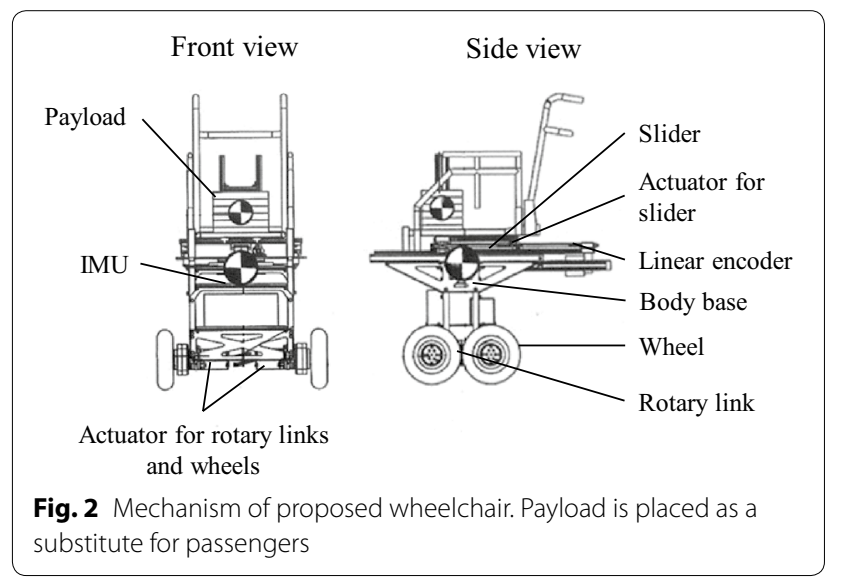




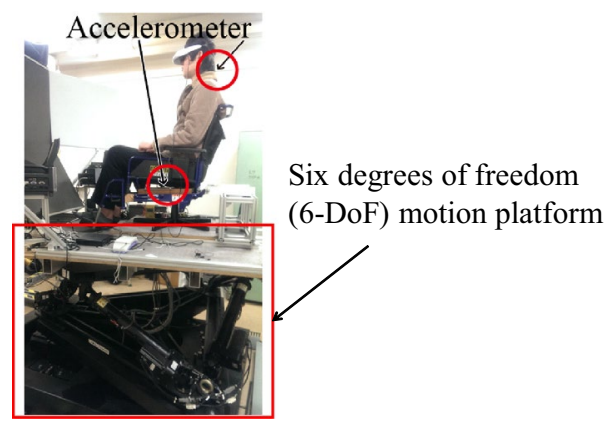

Fig. 3 Seat vibration experiment [1 1]

actuator has the adequate frequency response [5]. In addition, this EPW has a sensor for each actuator, and an inertial measurement unit to acquire the pitch angle of the EPW. A public facility is assumed as the operation environment for this EPW, and the dimensions of stairs should satisfy the Japanese Building Standards [12].

\section{Control strategy}

\section{System modeling}

As the control is symmetrical during climbing, we define the mechanism as a two-dimensional rigid model, as shown in Fig. 4, and derive the equation of motion [6]. The constant parameters and the prototype values are listed in Table 2 . There are six state variables: pitch angle $\theta_{\mathrm{bp}}$, rotation angle of the left rotary link $\theta_{\mathrm{ll}}$, rotation angle of the right rotary link $\theta_{\mathrm{rl}}$, rotation angle of the left wheel $\theta_{\mathrm{lw}}$, rotation angle of the right wheel $\theta_{\mathrm{rw}}$ and position of the slider $x_{\mathrm{s}}$. There are five inputs: left rotary link torque $\tau_{1 \mathrm{l}}$, right rotary link torque $\tau_{\mathrm{rl}}$, left grounding wheel torque $\tau_{\mathrm{lw}}$, right grounding wheel torque $\tau_{\mathrm{rw}}$ and slider force $F_{\mathrm{s}}$. There is no actuator for the pitch angle, and it is not driven. When the equation of motion is derived by the Lagrange method, it is expressed as follows, where $t$ is time and $L$ is the Lagrangian:

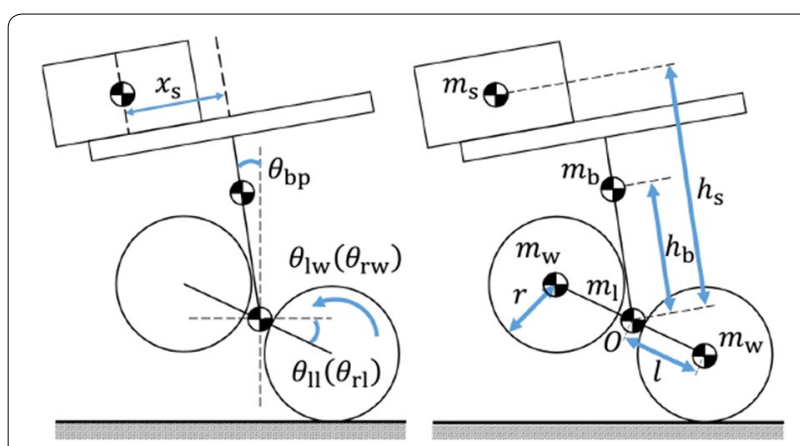

Fig. 4 Simplified model for design of control system

$$
\begin{gathered}
0=\frac{d}{d t}\left(\frac{\partial L}{\partial \dot{\theta}_{\mathrm{bp}}}\right)-\frac{\partial L}{\partial \theta_{\mathrm{bp}}} \\
\tau_{\mathrm{ll}}=\frac{d}{d t}\left(\frac{\partial L}{\partial \dot{\theta}_{\mathrm{ll}}}\right)-\frac{\partial L}{\partial \theta_{\mathrm{ll}}} \\
\tau_{\mathrm{rl}}=\frac{d}{d t}\left(\frac{\partial L}{\partial \dot{\theta}_{\mathrm{rl}}}\right)-\frac{\partial L}{\partial \theta_{\mathrm{rl}}} \\
\tau_{\mathrm{lw}}=\frac{d}{d t}\left(\frac{\partial L}{\partial \dot{\theta}_{\mathrm{lw}}}\right)-\frac{\partial L}{\partial \theta_{\mathrm{lw}}} \\
\tau_{\mathrm{rw}}=\frac{d}{d t}\left(\frac{\partial L}{\partial \dot{\theta}_{\mathrm{rw}}}\right)-\frac{\partial L}{\partial \theta_{\mathrm{rw}}} \\
F_{s}=\frac{d}{d t}\left(\frac{\partial L}{\partial \dot{x}_{\mathrm{s}}}\right)-\frac{\partial L}{\partial x_{\mathrm{s}}}
\end{gathered}
$$

\section{System control architecture}

The proposed mechanism allows for the climbing of stairs by switching between two operation modes: the center-ofgravity control phase and the rotary link control phase, as illustrated in Fig. 5. On a stair with a sufficiently long tread surface, the sequence shown in Fig. $5 \mathrm{~b}$ is used. The centerof-gravity control phase is a preparation phase for performing inverted pendulum control on the front wheels. The center of gravity of the EPW is moved above the front wheels by moving the slider when all the front and rear wheels are in contact with the ground. In this phase, the slider is moved to the target position, and proportional-differential control and gravity compensation are

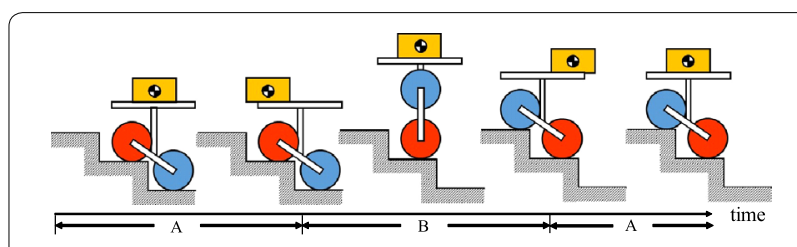

a Sequence of climbing stairs under conditions of short stair tread.

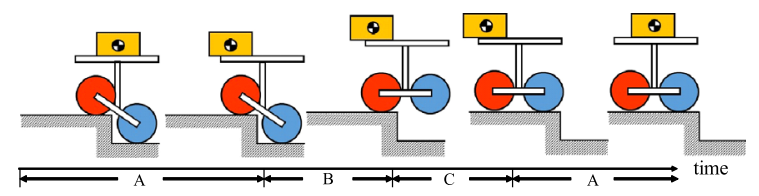

b Sequence of climbing stairs under conditions of long stair tread.

Fig. 5 Sequence of climbing stairs. a Center-of-gravity control phase, b Rotary link control phase, c Inverted movement control phase 


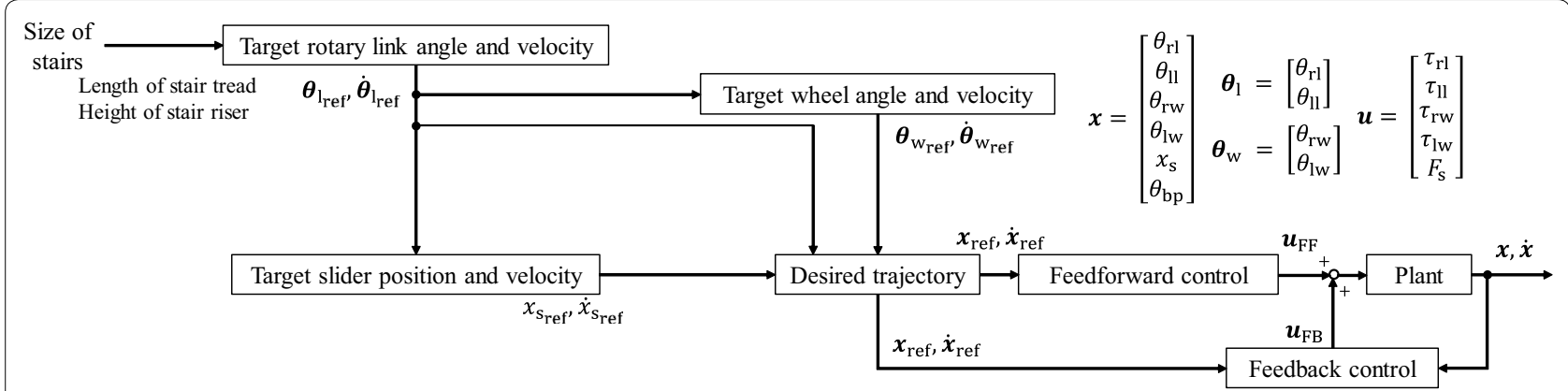

Fig. 6 Detailed control block diagram of system for climbing stairs

Table 2 Parameters of developed EPW

\begin{tabular}{lll}
\hline Parameter & Symbol & Value \\
\hline Wheel radius & $r$ & $0.125 \mathrm{~m}$ \\
Half-length of rotary link & $/$ & $0.13 \mathrm{~m}$ \\
Center of mass of body base & $h_{\mathrm{b}}$ & $0.2528 \mathrm{~m}$ \\
Center of mass of seat & $h_{\mathrm{s}}$ & $0.617 \mathrm{~m}$ \\
Mass of wheel & $m_{\mathrm{w}}$ & $1.65 \mathrm{~kg}$ \\
Mass of rotary link & $m_{\mathrm{l}}$ & $7.4 \mathrm{~kg}$ \\
Mass of body base & $m_{\mathrm{b}}$ & $50.0 \mathrm{~kg}$ \\
Mass of slider (including payload) & $m_{\mathrm{s}}$ & $98.5 \mathrm{~kg}$ \\
Total mass of wheelchair & $M$ & $169.9 \mathrm{~kg}$ \\
Inertia of wheel & $J_{\mathrm{w}}$ & $0.00965 \mathrm{kgm}^{2}$ \\
Inertia of rotary link & $J_{\mid}$ & $0.107 \mathrm{kgm}^{2}$ \\
Inertia of body base & $J_{\mathrm{b}}$ & $3.4 \mathrm{kgm}^{2}$ \\
Inertia of slider & $J_{\mathrm{s}}$ & $1.23 \mathrm{kgm}^{2}$
\end{tabular}

performed such that the rotation angle of the rotary links and wheels does not change. During the rotary link control phase, the rotary link is rotated, and the stairs are switched as inverted pendulum control is performed on the two front wheels. During this period, the target trajectory for the rotary link rotation angle is set from the stair shape, and the target trajectories for the wheel rotation angle and the slider position are calculated accordingly. As shown in Fig. 6, this controller combines feedforward control that provides actuator inputs to follow the target trajectory, and feedback control that compensates for disturbances and modeling errors to improve the ability to follow the target trajectory.

\section{Feedforward control}

Considering symmetrical control when climbing stairs, $\theta_{\mathrm{l}}$ means $\theta_{\mathrm{l}}=\theta_{\mathrm{ll}}=\theta_{\mathrm{rl}}$ and $\theta_{\mathrm{w}}$ means $\theta_{\mathrm{w}}=\theta_{\mathrm{lw}}=\theta_{\mathrm{rw}}$. The rotary link control phase is divided into three sections, as shown in Fig. 7, and the target trajectory of the rotary link angle $\theta_{\text {lref }}$ is set such that each section is smoothly connected [7]. The target trajectory for the wheel angle and

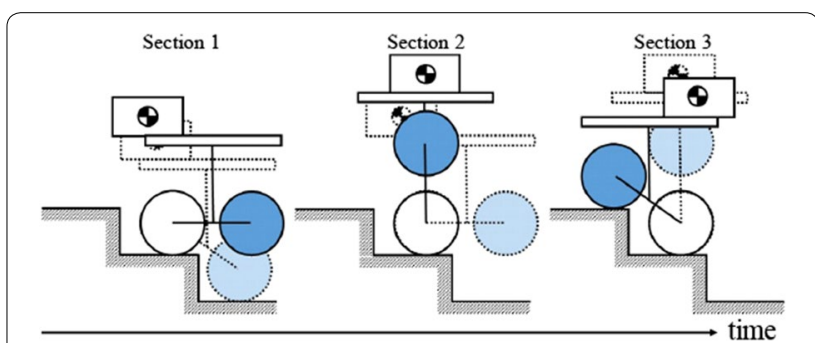

Fig. 7 Three sections in rotary link control phase

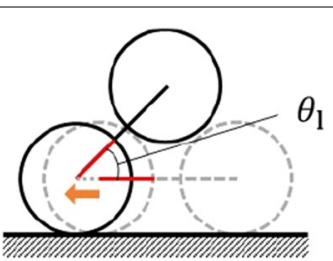

Fig. 8 Wheel rotation associated with rotary link rotation

slider position is set according to the target trajectory for the rotary link. When the rotary link rotates, the wheel also rotates owing to the structure of the mechanism, as shown in Fig. 8. Therefore, the target trajectory of the wheel angle $\theta_{\text {wref }}$ is assumed to be the reverse of the target trajectory of the rotary link angle, as shown in the Eq. (7).

$$
\theta_{\text {wref }}=-\theta_{\text {lref }}
$$

The target trajectory of the slider position is set such that the moment around the center axis of the grounding wheel is geometrically zero in the model shown in Fig. 4. Since the pitch angle $\theta_{\mathrm{bp}}$ must be maintained near zero, the target trajectory of the slider position $x_{\text {sref }}$ is expressed as the Eq. (8). The total weight of the wheelchair $\left(4 m_{\mathrm{w}}+2 m_{\mathrm{l}}+m_{\mathrm{b}}+m_{\mathrm{h}}\right)$ is written as $M$.

$$
x_{\text {sref }}=\frac{1}{2} \frac{M l}{m_{\mathrm{s}}}\left(\cos \left(\theta_{\mathrm{rl}}\right)+\cos \left(\theta_{\mathrm{ll}}\right)\right)
$$




\section{Feedback control}

By linearizing the derived Eq. (1)-(6), the state equation is obtained as the expression (9), where the state variable $\boldsymbol{x}_{k}$ and inputs $\boldsymbol{u}_{k}$ are defined as the expression (10) and (11), respectively. To eliminate the nonlinear terms, we made the following assumptions.

- $\dot{\theta}_{\mathrm{ll}}, \dot{\theta}_{\mathrm{rl}}, \dot{\theta}_{\mathrm{lw}}, \dot{\theta}_{\mathrm{rw}}, \dot{x}_{\mathrm{s}}$ and $\dot{\theta}_{\mathrm{bp}}$ are small and these quadratic terms are regarded as zero.

- From $\theta_{\mathrm{bp}} \simeq 0$, we set $\sin \left(\theta_{\mathrm{bp}}\right) \simeq \theta_{\mathrm{bp}} \simeq 0$ and $\cos \left(\theta_{\mathrm{bp}}\right) \simeq 1$.

- Slider position $x_{\mathrm{s}}$ satisfies Eq. (8).

In consideration of the backlash of the gear between the wheel and its actuator, the wheel angle feedback control is not performed. Therefore, the wheels angle $\theta_{\mathrm{lw}}$ and $\theta_{\mathrm{rw}}$ are not included in the state variables.

$$
\begin{aligned}
& \dot{\boldsymbol{x}}_{k}= \boldsymbol{A}_{13 \times 13}\left(\theta_{\mathrm{ll}}, \theta_{\mathrm{rl}}\right) \boldsymbol{x}_{k}+\boldsymbol{B}_{13 \times 5}\left(\theta_{\mathrm{ll}}, \theta_{\mathrm{rl}}\right) \boldsymbol{u}_{k} \\
& \boldsymbol{x}_{k}= {\left[\int \theta_{\mathrm{ll}}, \int \theta_{\mathrm{rl}}, \int \theta_{\mathrm{bp}}, \theta_{\mathrm{ll}}, \theta_{\mathrm{rl}}, \theta_{\mathrm{bp}}, x_{\mathrm{s}},\right.} \\
&\left.\dot{\theta}_{\mathrm{lw}}, \dot{\theta}_{\mathrm{rw}}, \dot{\theta}_{\mathrm{ll}}, \dot{\theta}_{\mathrm{rl}}, \dot{\theta}_{\mathrm{bp}}, \dot{x}_{\mathrm{s}}\right]^{T} \\
& \boldsymbol{u}_{k}=\left[\tau_{\mathrm{lw}}, \tau_{\mathrm{rw}}, \tau_{\mathrm{ll}}, \tau_{\mathrm{rl}}, F_{\mathrm{s}}\right]^{T}
\end{aligned}
$$

The state equation (9) is a function of the rotary link angle $\theta_{\mathrm{l}}$, and it is required to derive the feedback gain according to the rotary link angle. Therefore, we obtained 36 state equations at each angle where the rotary link angle is changed by $10 \mathrm{deg}$ from -180 to $180 \mathrm{deg}$. For each state equation, the feedback gain that minimizes the evaluation function shown in the Eq. (12) is obtained using optimal control theory.

$$
J(t)=\int_{0}^{\infty}\left[\boldsymbol{x}^{T}(t) \boldsymbol{Q} \boldsymbol{x}(t)+\boldsymbol{u}^{T}(t) \boldsymbol{R} \boldsymbol{u}(t)\right] d t
$$

$Q$ is the weighting matrix of the control state variables and $\boldsymbol{R}$ is the weighting matrix of the control inputs. Diagonal matrices are shown as Eqs. (13) and (14). In the matrix $Q$, the weight of the slider position and the pitch angle are set to be large, and the weight of the wheel angular velocity is set to be small to balance without falling.

$$
\begin{aligned}
\boldsymbol{Q}= & \operatorname{diag}[10,10,25000,4000000,4000000, \\
& 20000000,8000000,15000,15000, \\
& 50000,50000,800000,3000000]^{T} \\
\boldsymbol{R}= & \operatorname{diag}[18,18,1,1,0.1]^{T}
\end{aligned}
$$

From the above, feedback gains corresponding to discrete rotary link angles were obtained. Here, the feedback gain corresponding to the continuous rotary link angle is obtained by interpolation. Let $K(\alpha, \beta)$ be the feedback gain when the right rotary link angle is $\alpha$ and the left rotary link angle is $\beta$. Four feedback gains $\left(K\left(\alpha_{\mathrm{i}}, \beta_{\mathrm{j}}\right)\right.$, $\left.\boldsymbol{K}\left(\alpha_{\mathrm{i}+1}, \beta_{\mathrm{j}}\right), \boldsymbol{K}\left(\alpha_{\mathrm{i}}, \beta_{\mathrm{i}+1}\right), \boldsymbol{K}\left(\alpha_{\mathrm{i}+1}, \beta_{\mathrm{i}+1}\right)\right)$ with discrete rotary link angles close to $\alpha$ and $\beta$ are selected as shown in Fig. 9. When linear interpolation is performed on $\beta$, the two feedback gains $K\left(\alpha_{\mathrm{i}}, \beta\right)$ and $\boldsymbol{K}\left(\alpha_{\mathrm{i}+1}, \beta\right)$ are expressed as in Eqs. (15) and (16).

$$
\begin{aligned}
& \boldsymbol{K}\left(\alpha_{\mathrm{i}}, \beta\right) \\
& \quad=\boldsymbol{K}\left(\alpha_{\mathrm{i}}, \beta_{\mathrm{j}}\right)+\frac{\beta-\beta_{\mathrm{j}}}{\beta_{\mathrm{j}+1}-\beta_{\mathrm{j}}}\left(\boldsymbol{K}\left(\alpha_{\mathrm{i}}, \beta_{\mathrm{j}+1}\right)-\boldsymbol{K}\left(\alpha_{\mathrm{i}}, \beta_{\mathrm{j}}\right)\right)
\end{aligned}
$$

$$
\begin{aligned}
& \boldsymbol{K}\left(\alpha_{\mathrm{i}+1}, \beta\right) \\
& \quad=\boldsymbol{K}\left(\alpha_{\mathrm{i}+1}, \beta_{\mathrm{j}}\right)+\frac{\beta-\beta_{\mathrm{j}}}{\beta_{\mathrm{j}+1}-\beta_{\mathrm{j}}}\left(\boldsymbol{K}\left(\alpha_{\mathrm{i}}, \beta_{\mathrm{j}+1}\right)-\boldsymbol{K}\left(\alpha_{\mathrm{i}}, \beta_{\mathrm{j}}\right)\right)
\end{aligned}
$$

At this time, the feedback gain $K(\alpha, \beta)$ is expressed as in Eq. (17).

$$
\begin{aligned}
& \boldsymbol{K}(\alpha, \beta) \\
& \quad=\boldsymbol{K}\left(\alpha_{\mathrm{i}}, \beta\right)+\frac{\alpha-\alpha_{\mathrm{i}}}{\alpha_{\mathrm{i}+1}-\alpha_{\mathrm{i}}}\left(\boldsymbol{K}\left(\alpha_{\mathrm{i}+1}, \beta\right)-\boldsymbol{K}\left(\alpha_{\mathrm{i}}, \beta\right)\right)
\end{aligned}
$$

The feedback control inputs are calculated by the control law shown in Eq. (18) based on the obtained feedback gain $\boldsymbol{K}(\alpha, \beta)$.

$$
\boldsymbol{u}_{k}=\boldsymbol{K}(\alpha, \beta)\left(\boldsymbol{x}_{k \mathrm{ref}}-\boldsymbol{x}_{k}\right)
$$

\section{Experiments and discussion}

Experiment for determining characteristics

In this section, we determine the behavior of the mobile body as the climbing speed of stairs increases.

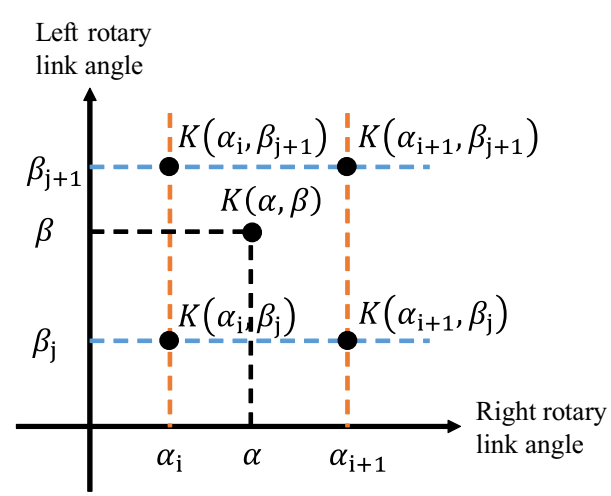

Fig. 9 Linear interpolation of gain 
Table 3 Time it takes to rotate rotary links

\begin{tabular}{lll}
\hline $\boldsymbol{T}=\boldsymbol{T}_{\mathbf{1}}+\boldsymbol{T}_{\mathbf{2 3}}[\mathrm{s}]$ & $\boldsymbol{T}_{\mathbf{1}}[\mathrm{s}]$ & $\boldsymbol{T}_{\mathbf{2 3}}[\mathrm{s}]$ \\
\hline 15 & 1 & 14 \\
10 & 1 & 9 \\
7.5 & 1 & 6.5 \\
5 & 1 & 4
\end{tabular}

\section{Experiment conditions}

Kawahata's study [7] shows that the amount of the grounding wheel movement in section 1 as shown in Fig. 6 is small, so the experiments were performed under the condition that time $T_{1}$ for section 1 was fixed at $1 \mathrm{~s}$, and time $T_{23}$ for sections 2 and 3 was changed as presented in Table 3. Based on the Building Standard Law, the height of the stairs was $0.14 \mathrm{~m}$.

\section{Experiment results and discussion}

From the results of the experiment shown in Fig. 10a, the amount of grounding wheel movement increased with the increase in the stair climbing speed. The changes in the pitch angle under the conditions of $T=15$ and $T=5$ are shown in Fig. 10b, c respectively. Although the pitch angle is maintained near zero, and the wheelchair does not fall, the grounding wheels move approximately $30 \mathrm{~cm}$ under the condition of $T=5$ from Fig. 10a. If the length of the tread is short, it collides with the side of the stair, leading to a fall of the wheelchair. Figure 11 shows the time series change of the actual grounding wheel position. If we look at the white marker, we can see the manner in which the wheels are rotating.

To theoretically understand the factors that increase the motion of the grounding wheels with an increase in the stair climbing speed, we focus on the equation of motion related to the nondriven pitch angle, as shown in Eq. (1). It is necessary to set the pitch angle to zero to prevent the wheelchair from falling. When Eq. (1) is expanded with $\theta_{\mathrm{bp}}=\dot{\theta}_{\mathrm{bp}}=\ddot{\theta}_{\mathrm{bp}}=0$, it can be expressed as follows:

$$
\begin{aligned}
0= & -m_{\mathrm{s}} g x_{\mathrm{s}}+M g l \cos \theta_{\mathrm{l}} \\
& +\left(4 J_{\mathrm{w}}+\left(M r+m_{\mathrm{s}} h_{\mathrm{s}}+m_{\mathrm{b}} h_{\mathrm{b}}\right.\right. \\
& \left.\left.+M l \sin \theta_{\mathrm{l}}\right) r\right)\left(\ddot{\theta}_{\mathrm{w}}+\ddot{\theta}_{\mathrm{l}}\right) \\
& +m_{\mathrm{s}}\left(r+h_{\mathrm{s}}+l \sin \theta_{\mathrm{l}}\right) \ddot{x}_{\mathrm{s}} \\
& +\left(4 J_{\mathrm{l}}+\left(M+4 m_{\mathrm{w}}\right) l^{2}\right) \ddot{\theta}_{\mathrm{l}} \\
& +\left(M r+m_{\mathrm{s}} h_{\mathrm{s}}+m_{\mathrm{b}} h_{\mathrm{b}}\right) l\left(\ddot{\theta}_{\mathrm{l}} \sin \theta_{\mathrm{l}}+\dot{\theta}_{\mathrm{l}}^{2} \cos \theta_{1}\right) \\
& -m_{\mathrm{s}} x_{\mathrm{s}} l\left(\ddot{\theta}_{\mathrm{l}} \cos \theta_{\mathrm{l}}-\dot{\theta}_{\mathrm{l}}^{2} \sin \theta_{\mathrm{l}}\right)
\end{aligned}
$$

The term (19) refers to the moment due to gravity, the term (20) refers to the moment due to the inertial force of the mobile body moving back and forth with the

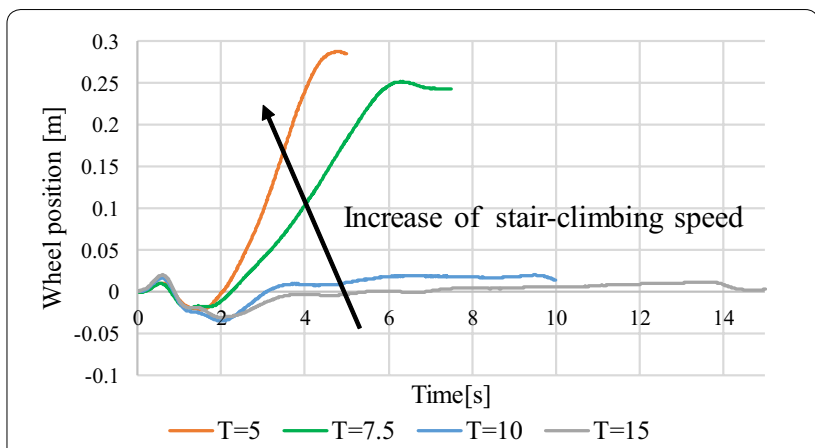

a Wheel position during climbing stairs.

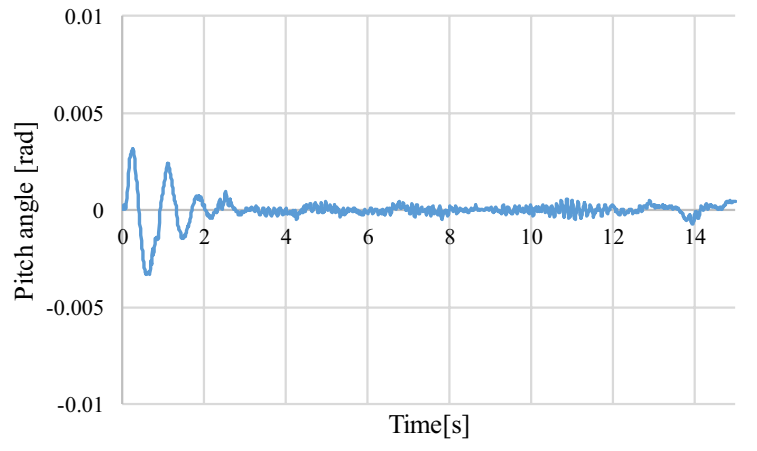

b Pitch angle when climbing stairs $(T=15)$.

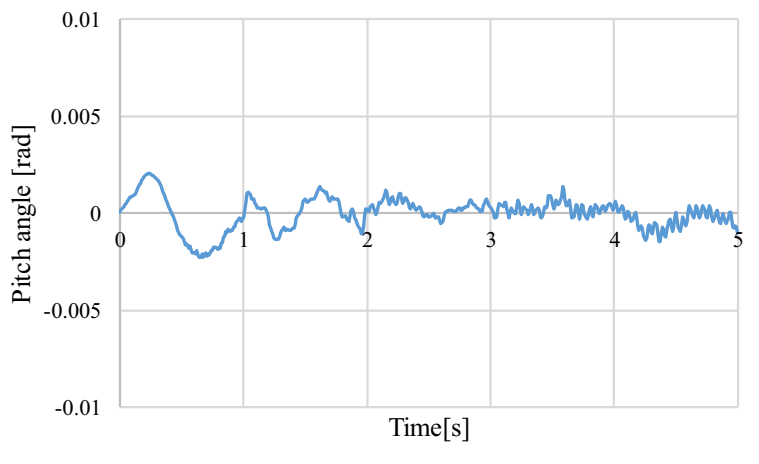

C Pitch angle when climbing stairs $(T=5)$.

Fig. 10 Results of experiment for determining characteristics

wheel rotation, and the term (21) refers to the moment due to the inertial force of the slider movement. The term (22) denotes the moment due to the inertial force of the rotary link rotation, the term (23) denotes the moment due to the inertial force of the mobile body moving back and forth with the rotary link rotation, and the term (24) refers to the moment due to the inertial force of the mobile body moving up and down with the rotary link rotation. As shown in Fig. 12, it can be seen that each element affects the pitch angle of the 


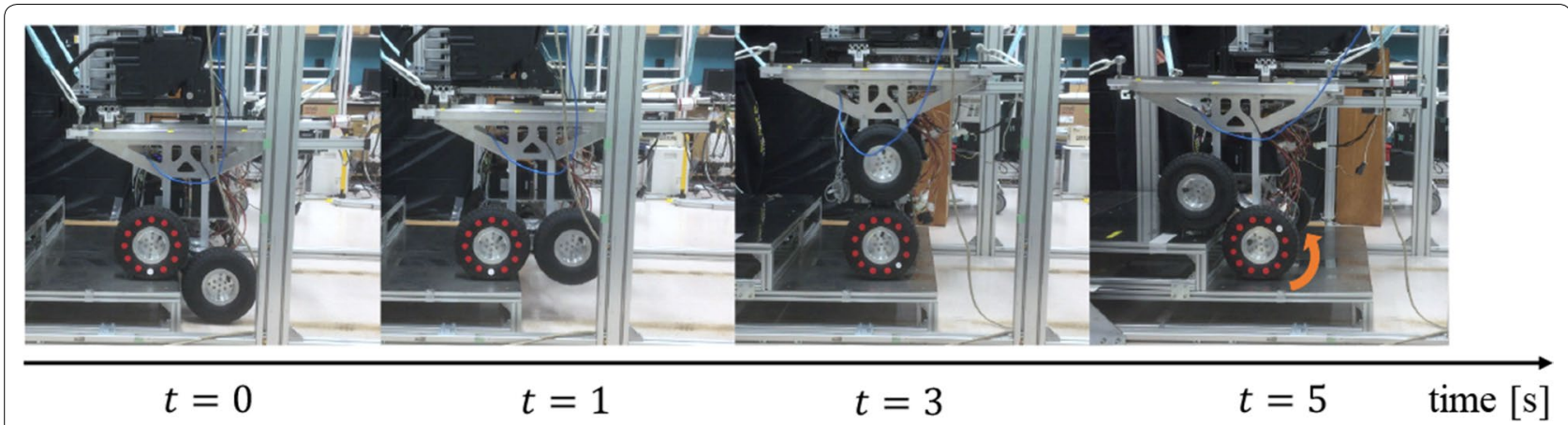

Fig. 11 Wheel movements when climbing stairs

mobile body during inverted pendulum control. The term (21) represents the effect of the force accompanying the slider movement, and the reaction force of the slider force $F_{\text {slider }}$ is considered to be affected. The term (22) represents the effect of the force accompanying the rotation of the rotary link, and the countertorque of the rotary link $\tau_{\text {link }}$ is considered to be affected.

The equation of motion expressed by the terms (19)(24) do not include the motor torque, and a conditional expression (hereinafter referred to as a dynamic equilibrium equation) is used to dynamically maintain the equilibrium state of the pitch angle zero when inverted. When the left and right wheels and the rotary links are controlled symmetrically, there are three degrees of freedom: wheel angle $\theta_{\mathrm{w}}$, rotary link angle $\theta_{\mathrm{l}}$, and slider position $x_{\mathrm{s}}$. However, this dynamic equilibrium equation does not allow the target trajectory to be set independently. Once the desired trajectory of the two degrees of freedom is determined, the remaining target trajectory is uniquely determined from the dynamic equilibrium equation [13].

Here, we discuss the current feedforward control and the behavior of the mobile body. First, it is necessary to set the target trajectory of the rotary link. In addition, since it is desirable that the grounding wheels on the stairs do not move, the current target trajectory for the wheels is adopted. In this case, the target trajectory of the slider must be set so that the moment due to the inertial force and reaction of the driving force expressed by the terms (21)-(24) and the moment due to gravity expressed by the term (19) can be compensated. However, the current target trajectory of the slider can only compensate for the gravitational term (19) as shown in Eq. (8). For this reason, feedforward control does not compensate for the effects of the inertial force and reaction of the driving force shown in the terms (21)-(24) on the pitch angle. That is, to maintain the pitch angle at zero, one of the wheel angles, the rotary link

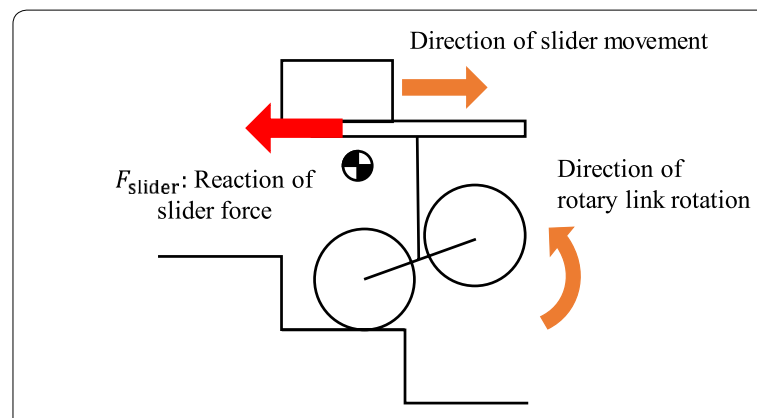

a Reaction of slider force

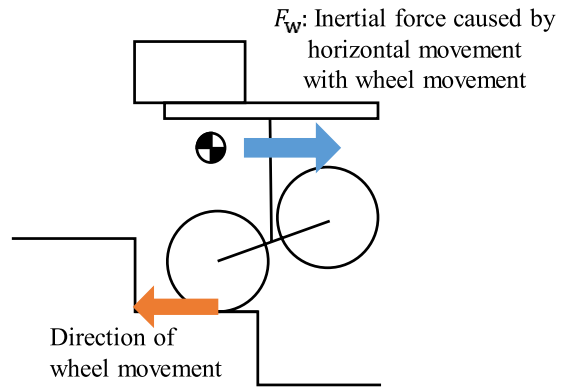

b Inertial force caused by horizontal movement of wheels

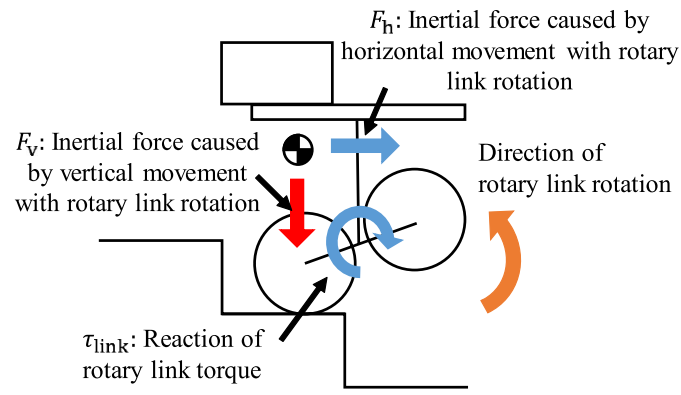

c Reaction of rotary link torque and inertial force caused by link rotation

Fig. 12 Inertial forces and reaction forces acting on pitch angle 
angle, and the slider position cannot theoretically follow the target trajectory.

Here, focusing on feedback control, since the wheel has a large gear backlash, the wheel angle is not feedback-controlled, and the feedback gain of the wheel angular velocity cannot be increased. In other words, the wheel angle has the lowest ability to follow the target trajectory. Therefore, the moment owing to the inertial force and the reaction of the driving force are converted to the moment owing to the inertial force of the wheel back-and-forth movement. That is, it is considered that the pitch angle of zero is maintained by adjusting $\ddot{\theta}_{\mathrm{w}}$ of the term (20).

When the stair climbing speed increases, the angular velocity and acceleration of the rotary link increase, and the slider acceleration $\ddot{x}_{\mathrm{s}}$ also increases because it is expressed as a function of $\theta_{1}$ as shown in the expression (25). In other words, an increase in the stair climbing speed leads to an increase in the moment acting on the pitch angle indicated by the terms (21)-(24). To compensate for this moment and maintain the pitch angle at zero, a moment owing to the inertial force of the back-and-forth acceleration of the grounding wheels is generated.

Based on the abovementioned facts, the back-and-forth acceleration of the grounding wheels is considered to increase and the moving amount of the grounding wheels to increase with an increase in the stair climbing speed.

$$
\ddot{x}_{\text {sref }}=-\frac{M l}{m_{\mathrm{s}}}\left(\left(\ddot{\theta}_{\mathrm{l}} \sin \theta_{\mathrm{l}}+\dot{\theta}_{\mathrm{l}}^{2} \cos \theta_{\mathrm{l}}\right)\right)
$$

\section{Control considering dynamic equilibrium Control method}

By substituting the target trajectory of the rotary link and the wheel into the dynamic equilibrium equation and solving the equation of motion for $x_{\mathrm{s}}$, it is possible to derive the slider target trajectory considering the dynamic equilibrium. However, owing to the dynamic friction caused by the movement of the slider and the rotary link when climbing stairs, an error occurs between the theoretical slider target trajectory and the slider target trajectory that can compensate the dynamic balance in the actual machine. Therefore, we aim to suppress the grounding wheel movement by considering the moment acting on the pitch angle.

As described in the previous chapter, the moment acting on the pitch angle is compensated by the moment $M_{\mathrm{w}}$ generated by the inertial force of the wheel's back-and-forth movement. Therefore, as shown in Fig. 13, a control target generates moment $M_{\mathrm{s}}$ as a moment equivalent to $M_{\mathrm{w}}$ by changing the center-of-gravity position with a slider movement to suppress the grounding wheel movement.

From the term (20) of the dynamic equilibrium equation, the moment $M_{\mathrm{w}}$ due to the inertial force of the wheels' back-and-forth movement is expressed by Eq. (27) using the relationship of Eq. (26). In addition, the moment $M_{\mathrm{s}}$ generated when the slider is moved by $\Delta x$ is defined as the following Eq. (28):

$$
\begin{aligned}
& \ddot{\theta}_{\mathrm{w}}+\ddot{\theta}_{\mathrm{l}}=\frac{\ddot{x}_{\mathrm{w}}}{r} \\
& M_{\mathrm{w}}=\left(4 J_{\mathrm{w}}+\left(M r+m_{\mathrm{s}} h_{\mathrm{s}}+m_{\mathrm{b}} h_{\mathrm{b}}+M l \sin \theta_{\mathrm{l}}\right) r\right)\left(\frac{\ddot{x}_{\mathrm{w}}}{r}\right) \\
& M_{\mathrm{s}}=-m_{\mathrm{s}} g \Delta x
\end{aligned}
$$

$M_{\mathrm{w}}$ and $M_{\mathrm{s}}$ need to be equivalent to compensate the moment acting on the pitch angle not by $M_{\mathrm{w}}$ but by $M_{\mathrm{s}}$. At this time, the change amount $\Delta x$ of the slider target position necessary to compensate the dynamic equilibrium by adjusting the slider position is expressed as Eq. (29).

$$
\Delta x=-\frac{4 J_{\mathrm{w}}+\left(M r+m_{\mathrm{s}} h_{\mathrm{s}}+m_{\mathrm{b}} h_{\mathrm{b}}+M l \sin \theta_{\mathrm{l}}\right) r}{m_{\mathrm{s}} g r} \ddot{x}_{\mathrm{w}}
$$

From Eq. (29), if the back-and-forth acceleration of the wheel $\ddot{x}_{\mathrm{w}}$ is known, then $\Delta x$ can be obtained. However, $\ddot{x}_{\mathrm{w}}$ is a state quantity that appears because of climbing and is not an observable state quantity. Therefore, we consider estimating $\ddot{x}_{\mathrm{w}}$. From Fig. 10a, it is shown that the grounding wheel acceleration increases as the climbing speed increases. Therefore, we experimentally obtaine the relationship between the stair climbing speed and the grounding wheel acceleration.

As described in the previous chapter, the target trajectory of the rotary link is divided into three sections, as shown in Fig. 6 and is set in each section. The rotary link angular velocity in section 2 is assumed to be a constant. Therefore, a climbing experiment was performed in which the rotary link angular velocity in section 2 was changed from $0.1 \mathrm{rad} / \mathrm{s}$ to $0.9 \mathrm{rad} / \mathrm{s}$ every $0.1 \mathrm{rad} / \mathrm{s}$, and the grounding wheel acceleration was observed. Consequently, as shown in Fig. 14, the square of the rotary link

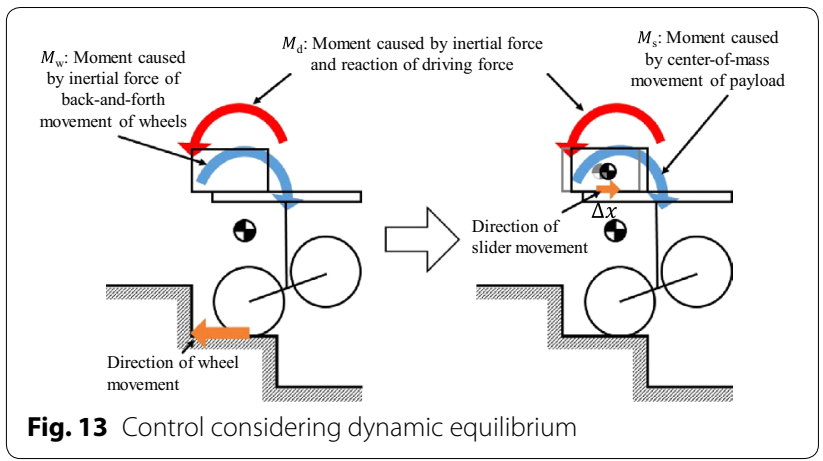


angular velocity and the grounding wheel acceleration have a linear relationship. Using Eq. (30), we found that the estimated value of the grounding wheel acceleration $\hat{\ddot{x}}_{\mathrm{w}}$ can be obtained from the rotary link angular velocity.

$$
\hat{\ddot{x}}_{\mathrm{w}}=0.1147\left(\dot{\theta}_{\text {lref }}^{2}-0.1709\right)
$$

$\Delta x$ can be derived by substituting the expression (30) into the expression (29). However, when $\hat{\ddot{x}}_{\mathrm{w}} \leq 0, \Delta x=0$. Equation (30) indicates that when the rotary link angular velocity $\dot{\theta}_{\text {lref }}$ satisfies $\dot{\theta}_{\text {lref }}^{2}>0.1709$, the grounding wheel acceleration occurs due to the inertial force and the the reaction of driving force, and the equilibrium state is statically maintained under the condition of $\dot{\theta}_{\text {lref }}^{2} \leq 0.1709$. By using $\Delta x$, the slider target trajectory considering dynamic equilibrium of the pitch angle can be expressed by Eq. (31).

$$
x_{\text {srefdyn }}=\frac{1}{2} \frac{M l}{m_{\mathrm{s}}}\left(\cos \left(\theta_{\mathrm{rl}}\right)+\cos \left(\theta_{\mathrm{ll}}\right)\right)+\Delta x
$$

A block diagram of the control to generate the slider target trajectory considering the dynamic equilibrium is shown in Fig. 15.

\section{Verification experiment for effectiveness}

We applied the control to change the slider target position by $\Delta x$ to sections 2 and 3, where the moving amount of the grounding wheels is large. Climbing experiments were conducted under the conditions of a step height of $0.14 \mathrm{~m}$ and rotary link control phase of $5 \mathrm{~s}$.

\section{Experiment results and discussion}

As shown in Fig. 16, the wheel angular velocity deviation tends to decrease, and the amount of grounding wheel movement decreases. However, the primary goal is to theoretically obtain a wheel angular velocity deviation of zero, which indicates that the moment

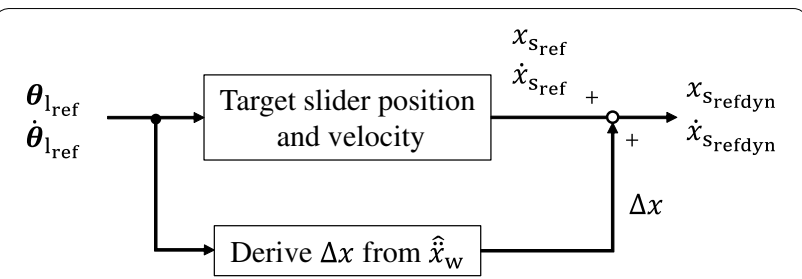

Fig. 15 Control block considering dynamic equilibrium

acting on the pitch angle cannot be fully compensated by the moment due to gravity. This can be attributed to the failure to follow sudden changes in the slider target value by $\Delta x$ at the transition from section 1 to section 2 , as shown in Fig. 17. In addition, as shown in Fig. 18, the amount of movement of the grounding wheels was within the allowed range, but increased after $2 \mathrm{~s}$, and therefore, it cannot be said that the wheelchair can climb stairs in a stable manner. Therefore, further improvement is necessary. In this result, based on the geometrical relationship shown in Fig. 19, the allowed range of the grounding wheel movement is calculated as the range for which the grounding wheels do not collide with the side of the stairs or slip off the edge of the stairs under the conditions of a step length of $0.26 \mathrm{~m}$, which is the shortest length in public facilities.

\section{Control for improving following performance}

In the previous section, we clarified that the slider position cannot follow the target value when transitioning from section 1 to section 2 . Therefore, to improve the ability to follow the slider target trajectory, as shown in formula (32), we consider a strategy to update the target value sequentially according to the deviation between the slider position measurement value $x_{s}$ and the target value considering dynamic equilibrium $x_{\text {srefdyn }}$. A block diagram of this control is shown in Fig. 20.

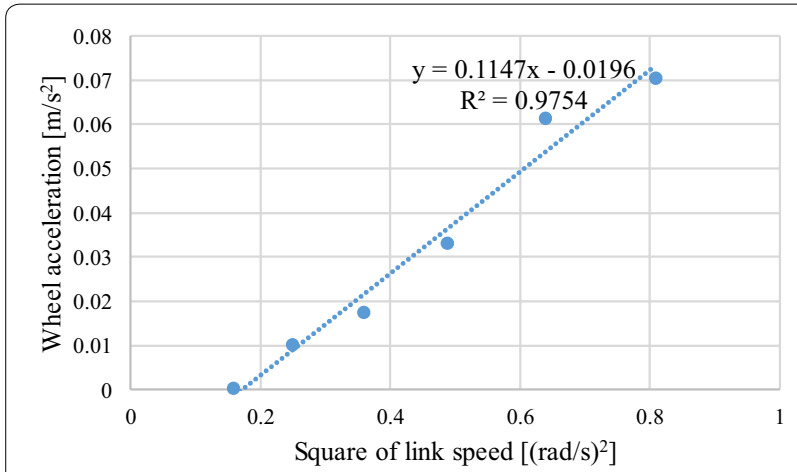

Fig. 14 Relationship between square of link angular velocity and wheel acceleration

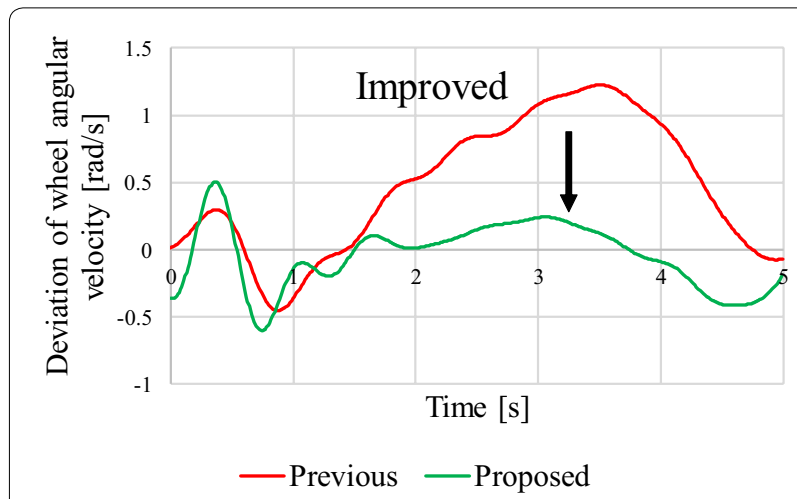

Fig. 16 Deviation of wheel angular velocity when climbing stairs 


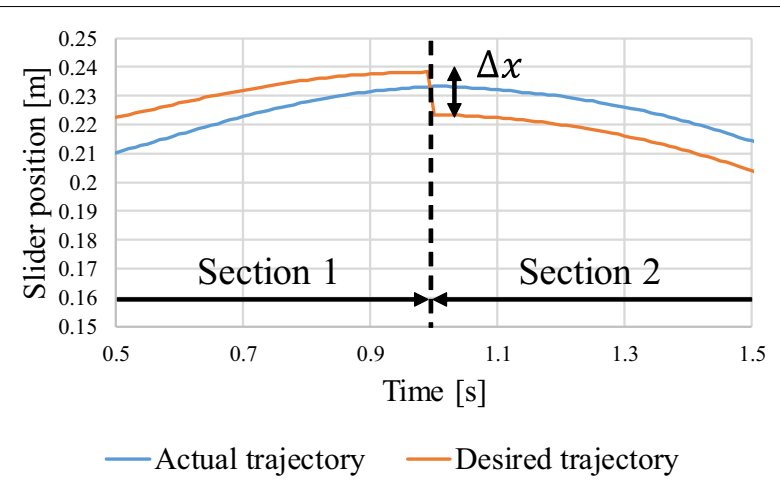

Fig. 17 Slider position at transition from section 1 to section 2

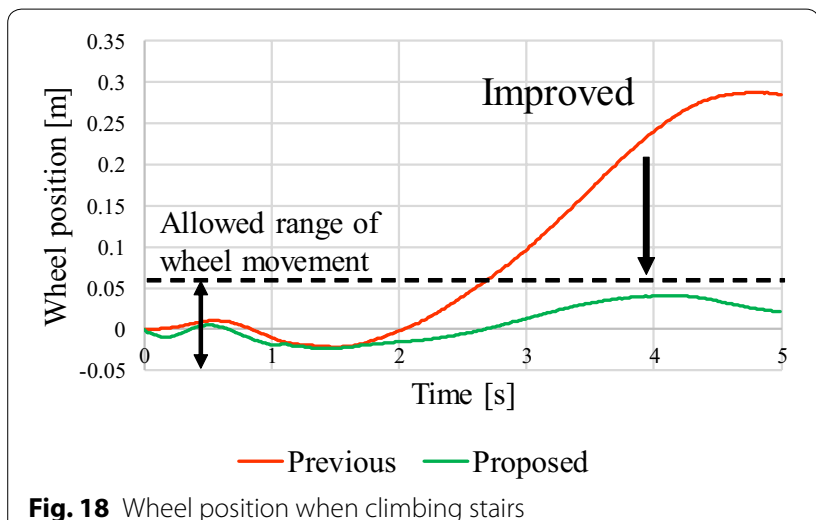

Fig. 18 Wheel position when climbing stairs

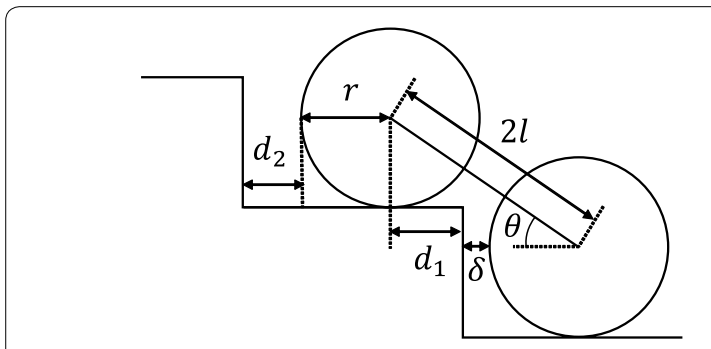

Fig. 19 Geometric relationship between stairs and wheels

$$
x_{\text {srefnew }}=x_{\text {srefdyn }}+K\left(x_{\text {srefdyn }}-x_{\mathrm{s}}\right)
$$

Here, as shown in Fig. 21, the value of $K$ was experimentally determined to minimize the forward-and-backward grounding wheel movement. In this study, the value of $K$ was set to 0.1 .

\section{Experiment to verify effectiveness of two proposed control methods}

After adding a new strategy to update the slider target position, we conducted an experiment under the

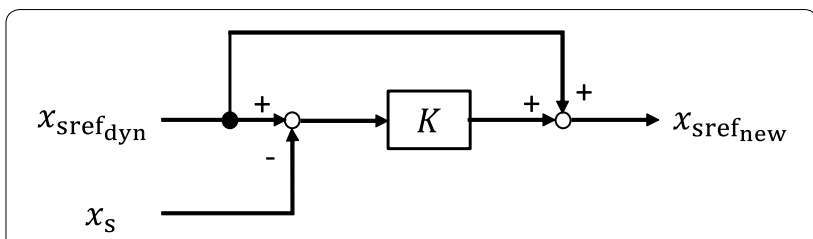

Fig. 20 Control for improving following performance of slider

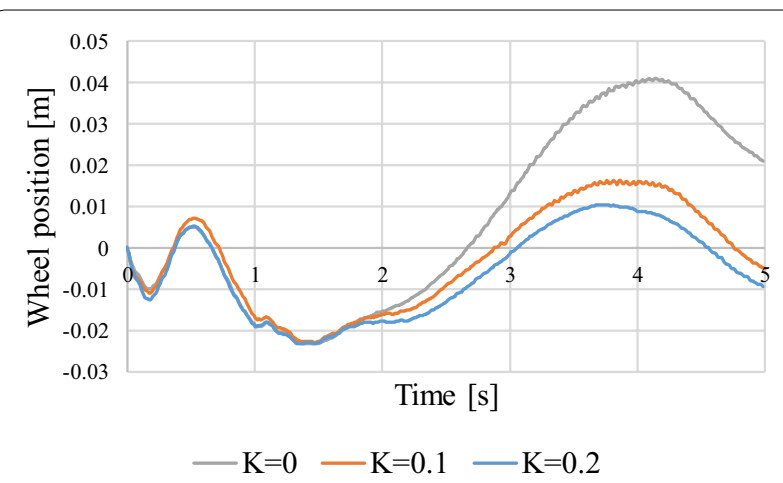

Fig. 21 Adjustment of coefficient for proposed control

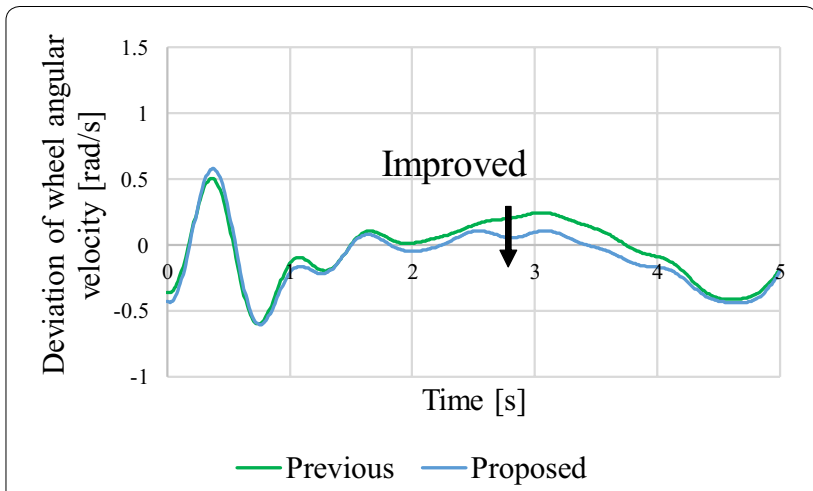

Fig. 22 Wheel angular velocity error when climbing stairs

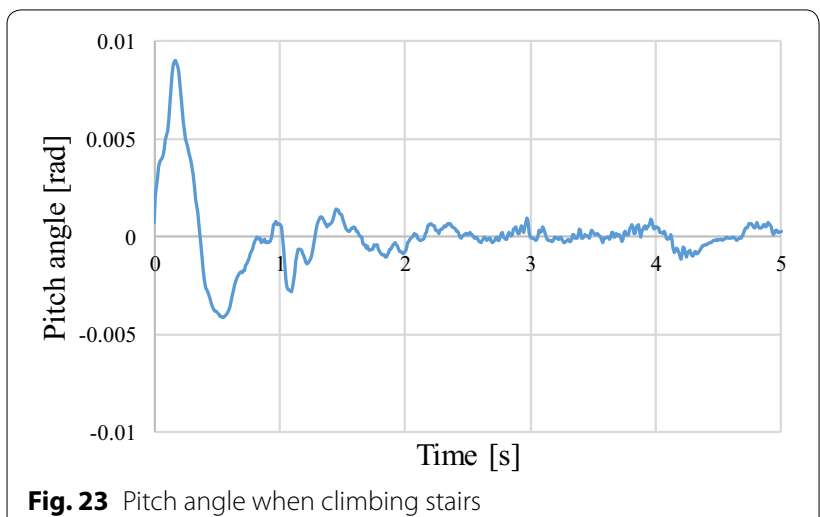




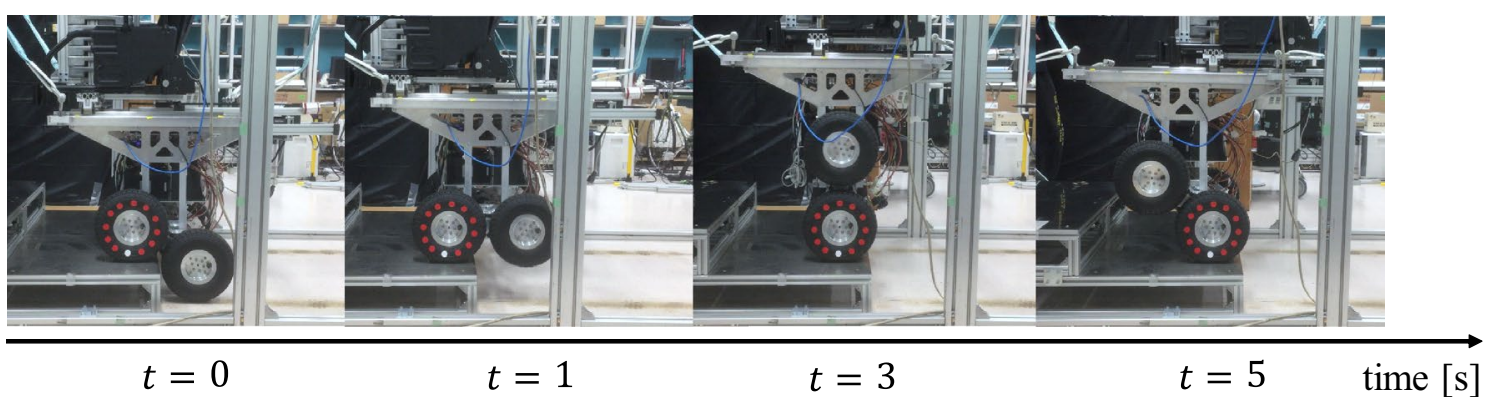

Fig. 24 Wheel movement when climbing stairs

conditions of a step height of $0.14 \mathrm{~m}$ and rotary link control phase of $5 \mathrm{~s}$.

\section{Experiment results and discussion}

As shown in Fig. 22, the wheel angular velocity deviation was smaller than before, and the deviation could be suppressed to nearly zero. In addition, as shown in Fig. 23, the pitch angle was suppressed to approximately zero even after applying the two proposed control methods. Focusing on the white marker in Fig. 24, it can be seen that the marker is not moving significantly, and that the movement of the grounding wheels is in fact suppressed.

Comparing the transition of the grounding wheel position before and after the application of the two proposed control methods, as shown in Fig. 25, the grounding wheel acceleration is observed to be suppressed by the application of the methods. It can therefore be said that the moment acting on the pitch angle was compensated by the moment due to gravity. Consequently, the amount of movement of the grounding wheels was within the allowed range, and stable climbing was achieved under the condition of a rotary link control phase of $5 \mathrm{~s}$. Figure 26 shows a block diagram with the two proposed controls and they are surrounded by a red line.

\section{Demonstration experiment}

Figure 27 shows the manner in which the proposed mechanism allows the chair to climb multiple stairs using the mentioned controllers under similar conditions. However, the second step is based on the sequence depicted in Fig. 5b. It takes $24 \mathrm{~s}$ to complete the ascent to the second step, and the ascending speed per step is not fast. Although the speed of the rotary link control phase was improved, the center-of-gravity control phase took approximately $10 \mathrm{~s}(9 \mathrm{~s}$ to $19 \mathrm{~s})$, and further improvement is necessary.

\section{Conclusions}

In this study, we proposed a method to improve the stability of an inverted-pendulum-type robotic wheelchair by controlling the center of gravity by a slider mechanism when the stair climbing speed is increased. As a problem encountered when climbing stairs at high speed, the inertial force and reaction of the driving force generated by the rotation of the rotary link and the movement of the slider affect the nondriving pitch angle. Therefore, to compensate for these effects, the grounding wheels move, which lead to the falling of the wheelchair. Therefore, to reduce the amount of grounding wheel movement, the slider target position was updated and a controller that can compensate for the dynamic equilibrium of the pitch angle using the updated target position.

In addition, it was demonstrated that using the constructed controller, the movement of the grounding wheels was greatly suppressed, and it was possible to stably climb stairs under the conditions of a step height of $0.14 \mathrm{~m}$ and rotary link control phase of $5 \mathrm{~s}$.

In future work, we will improve the functional safety when a user operates the EPW and propose corresponding safety measures.

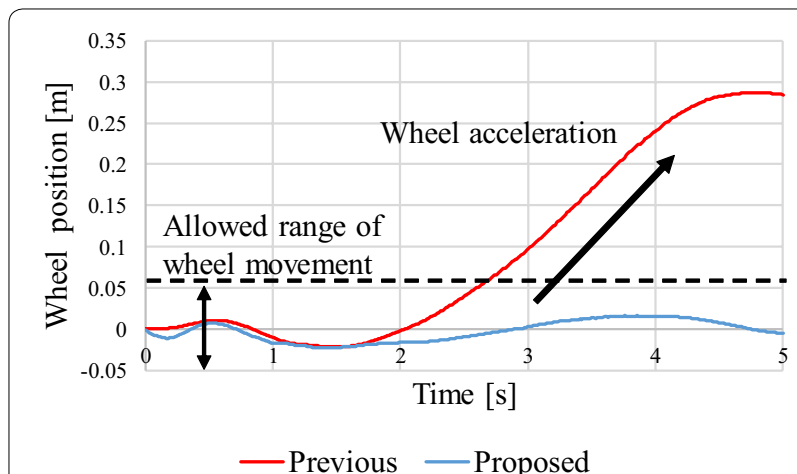

Fig. 25 Comparison of grounding wheel movement before and after applying proposed methods 


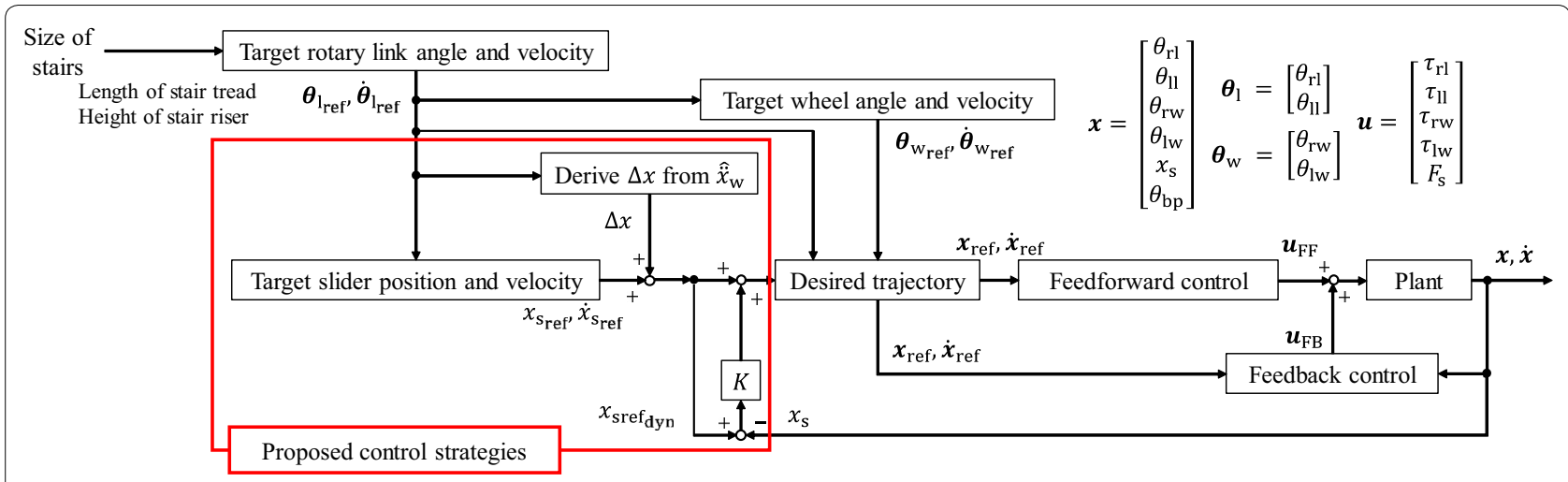

Fig. 26 Proposed control block diagram of system for climbing stairs
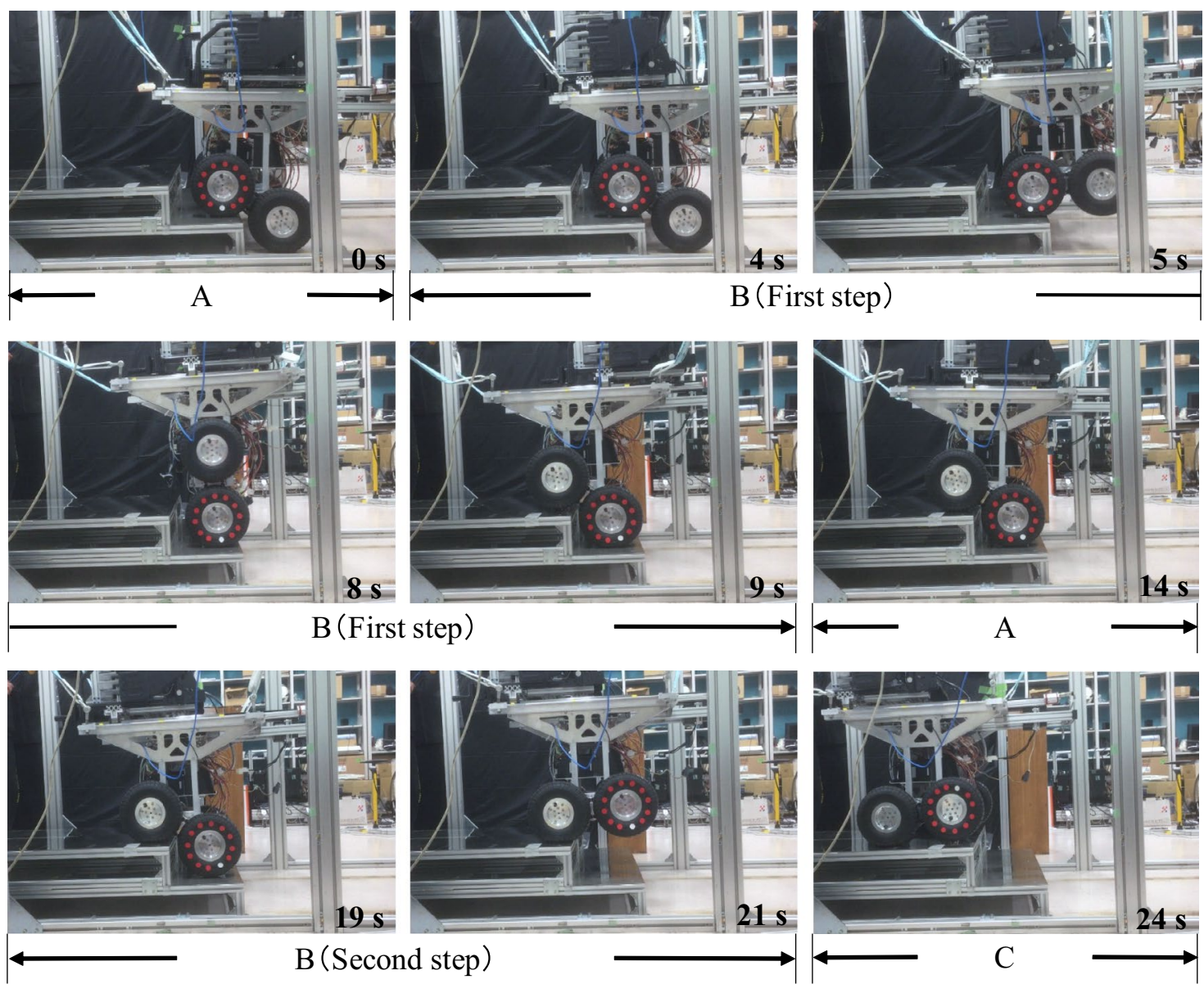

A: Center-of-gravity control phase B: Rotary link control phase C: Inverted movement phase

Fig. 27 Demonstration experiment when climbing stairs

\section{Acknowledgements}

This research is supported by JTEKT Co.Ltd.

We would like to thank Editage (http://www.editage.com) for English language editing.
Authors' contributions

MS, NT, and GM proposed the basic concept of overall system and constructed the prototype. YO performed the experiments for improving the 
stability of the system and was a major contributor in writing the manuscript. All authors read and approved the final manuscript.

\section{Funding}

Not applicable.

\section{Availability of data and materials}

Please contact the authors for data requests.

\section{Competing interests}

The authors declare that they have no competing interests.

\section{Author details}

1 Department of Human and Engineered Environmental Studies, Graduate School of Frontier Sciences, The University of Tokyo, 5-1-5 Kashiwanoha, Kashiwa, Chiba, Japan. ${ }^{2}$ Department of Robotics, Kindai University, 1 Takaya Umenobe, Higashi-Hiroshima, Hiroshima, Japan. ${ }^{3}$ JTEKT Corporation, 1-7 Kitajizozan, Noda-cho, Kariya, Aichi, Japan.

Received: 31 December 2019 Accepted: 6 May 2020

Published online: 16 May 2020

\section{References}

1. SCEWO, Bro-Scewo. https://scewo.ch/en/bro/. Accessed 30 Dec 2019

2. Nakajima S (2011) RT-Mover: a rough terrain mobile robot with a simple leg-wheel hybrid mechanism. Int J Rob Res 30(13):1609-1626. https://doi. org/10.1177/0278364911405697

3. Candiotti J, Sundaram A, Daveler B, Gebrosky B, Grindle G, Wang H, Cooper R (2017) Kinematics and Stability Analysis of a Novel Power Wheelchair When Traversing Architectural Barriers. Top Spinal Cord Inj Rehabil 23(2):110-119. https://doi.org/10.1310/sci2302-110

4. Uustal H, Minkel JL (2004) Study of the independence IBOT 3000 mobility system: An innovative power mobility device, during use in community environments. Arch Phys Med Rehabil 85(12):2002-2010. https://doi. org/10.1016/j.apmr.2004.04.044

5. Shino M, Tomokuni N, Murata G and Segawa M (2014) Wheeled inverted pendulum type robotic wheelchair with integrated control of seat slider and rotary link between wheels for climbing stairs. In: 2014 IEEE International Workshop on Advanced Robotics and its Social Impacts 121-126. https://doi.org/10.1109/ARSO.2014.7020991
6. Ding N, Shino M, Tomokuni N, Murata G (2017) Fall Avoidance Control of Wheeled Inverted Pendulum Type Robotic Wheelchair While Climbing Stairs. Word Academy of Science, Engineering and Technology, International Journal of Biomedical and Biological Engineering 11(4):168-175. https://doi.org/10.5281/zenodo.1130193

7. Kawahata R, Shino M, Ota S, Tomokuni N and Murata G (2018) Motion control of pendulum type robotic wheelchair considering mutual interference behavior between wheel and rotary links in climbing stairs. The Proceedings of JSME annual Conference on Robotics and Mechatronics (Robomech), 1P2-G06 2018 [in Japanese]. https://doi.org/10.1299/jsmer md.2018.1P2-G06

8. Matsumoto O, Kajita S, Tani K, Ohto M (1995) A Four-wheeled Robot to Pass Over Steps by Changing Running Control Modes. Journal of the Robotics Society of Japan 13(6):822-829. https://doi.org/10.7210/ jrsj.13.822

9. Matsumoto O, Kajita S, Tani K, Igura K (1997) Fast Passing Over Steps by a 'Variable Structure Type Four-wheeled Robot'Using a Dynamic Trajectory Planning Method for a Manipulator with Passive Joint. Journal of the Robotics Society of Japan 15(6):911-917. https://doi.org/10.7210/ jrsj.15.911

10. Matsumoto O, Kajita S, Saigo M, Tani K (2000) Dynamic Control of Fast Passing Over Stairs by a Biped Type Leg-wheeled Robot Considering the Continuity of Dynamic Trajectories. Journal of the Robotics Society of Japan 18(1):94-101. https://doi.org/10.7210/jrsj.18.94

11. Kodama R, Shino M, Tomokuni N, Murata G and Segawa M (2015) Motion Control of the Inverted Pendulum Type Stair-climbing Powered Wheelchair Considering Driver's Dynamic Response. 20th Robotics Symposia ISSN1881-7300:102-107 [in Japanese]

12. Enforcement Ordinance of Construction Standard Law, Articles 23-27, (1950)

13. Arai H, Tachi S (1991) Dynamic control of a manipulator with passive joints in an operational coordinate space. Proceedings. 1991 IEEE International Conference on Robotics and Automation 2:1188-1194. https://doi. org/10.1109/ROBOT.1991.131771

\section{Publisher's Note}

Springer Nature remains neutral with regard to jurisdictional claims in published maps and institutional affiliations.

\section{Submit your manuscript to a SpringerOpen ${ }^{\circ}$ journal and benefit from:}

- Convenient online submission

- Rigorous peer review

- Open access: articles freely available online

- High visibility within the field

- Retaining the copyright to your article

Submit your next manuscript at springeropen.com 